\title{
PENGARUH GAYA KEPE MIMPINAN DAN BUDAYA ORGANISASI TERHADAP KINERJA \\ KARYAWAN PADA BANK BTN KANTOR CABANG TANGERANG
}

\section{Denok Sunarsi *), Ine Yuliani}

Staf Pengajar Fakultas Ekonomi Universitas Pamulang

Email: denoksunarsi@gmail.com ${ }^{*}$

\begin{abstract}
ABSTRAK
Penelitia $\mathrm{n}$ ini memiliki tujuan untuk mengetahui $\mathrm{p}$ engaruh gaya ke pemimpinan dan budaya organisasi terhadap kiner ja karyawan pada Bank BTN Kantor Cabang Tangerang. Metode penelitian ini adalah analisis deskriptif kuantitatif. Dan menggunakan sebanyak 67 responden dengan m enggunakan Random Sampling dan pengambilan data dengan rumus Solvin. Hasil penelitiandapat dilihat dari Uji F yang memberikan hasil Fhitung > Ftabel $(33,173>3,140)$ maka Ha diterima, sehingga dinyatakan bahwa memiliki pengaruh yang positif dan signifikan secara simultan antara variabel gaya kepemimpinan dan budaya organisasi terhada $\mathrm{p}$ kinerja karyawan Bank BTN Kantor Cabang Tangerang.
\end{abstract}

Kata Kunci : "Gaya Kepemimpinan,Budaya Organisasi,Kinerja Karyawan”.

\section{ABSTRACT}

This stu dy aims to de termine the effect of lead ership style and organi zational cul ture on emp loyee performance at Bank BTN Tangerang Branch Office. This research method is quantitative descriptive analysis. The sample of this study was 67 respondents using Random Sampling and data collection using Solvin formula. The results of the study can be seen from the $F$ Test which gives the results of $F$ count $>F$ table $(33,173>3,140)$ then Ha is accepted, the variables of leadership style and organizational culture on the performance of Bank BTN employees .

Keywords: "Leadership Style, Organizational Culture, Employee Performance".

\section{P ENDAHULUAN}

\section{A. Latar Belakang Masalah}

Supaya tujuan perusahaan dalam mening katkan kinerja karyawan tercapai sudah menjadi kewajiban untuk memberikan motivasi agar lebih meningkatkan loyalitas pada peru sahaan. Menurut Hariandja (2011) "Kinerja karyawan adalah apa yang mempengaruhi seberapa banyak mereka memberi kontribusi kepada organisasi".

Berdasarkan hasil survey awal, diketahui bahwa gaya kepemimpinan Bank
BTN Kantor Cabang Tangerang yaitu gaya kepemimpinan Birokratisdan kinerja karyawannya diketahui mengalami fluktuatif.

Budaya Organisasi di Bank BTN Kantor Cabang Tangerang telah merumuskan "POLA PRIMA" yaitu "pelayanan prima (service excellent), inovasi (innovation), keteladanan (role model), profesionalisme (profesionalism), integritas (integrity), kerjasama (teamwork) ". Kelima kata itu memiliki makna sehingga mendorong kepada semua karyawannya untuk meningkatkan prestasi 
terutama dalam melayani perkreditan masyarakat . Berdasarkan hasil survey di Bank BTN Kantor Cabang Tangerang, banyak karyawan yang kurang tanggap dan peduli terhadap keinginan nasabah, terlihat dari hal sederhana sebagian sikap karyawan yang jarang senyum dan bersikap ramah, sehingga terlihat budaya organisasinya yang belum kondusif.

Kinerja Karyawan pada Bank BTN Kantor Cabang Tangerang berpengaruh pada pengetahuan kerja yang diberikan oleh pimpinan terlalu sedikit, sedangkan jumlah karyawan yang kurang banyak di beberapa divisi menyebabkan beberapa karyawan sering mengambil jam lembur.

Berdasarkan tabel hasil penelitian kinerja karyawan diatas, dapat dilihat bahwa telah terjadi penurunan kinerja karyawan setiap tahunnya pada Bank BTN kantor Cabang Tangerang. Hal ini dapat dilihat dari hasil penilaian kinerja karyawan selama 3 tahun yang berlangsung dari tahun 2015 hingga tahun 2017. Namun terjadi penurunan kinerja secara signifikan pada tahun 2017, sehingga target tidak didapat secara baik atau sempurna. Berdasarkan penjelasan tersebut, penulis meneliti dengan judul : “ Pengaruh Gaya Ke pemimpinan Dan Budaya O rganisasi Terhadap Kinerja Karyawan Pada Bank BTN Kantor Cabang Tangerang".

\section{B. Identifikasi Masalah}

Adapun identifikasi masalah sebagai berikut :

1. Gaya kepemimpinan birokratis masih berlaku pada Bank BTN Kantor Cabang Tangerang.

2. Kurang perhatiannya pimpinan terhadap karyawanpada Bank BTN Kantor Cabang Tangerang.
3. Budaya organisasi pada Bank BTN Kantor Cabang Tangerang yang tidak kondusif.

4. Karyawan pada Bank BTN Kantor Cabang Tangerang kurang tanggap dan peduli terhadap keinginan nasabah.

5. Karyawan pada Bank BTN Kantor Cabang Tangerang belum bekerja secara optimal.

6. Karyawan pada Bank BTN Kantor Cabang Tangerang belum menerapkan ketepatan waktu yang baik dalam penyelesaian pekerjaan.

\section{Rumusan Masalah}

Berdasarkan oleh pembatasan masalah diatas, maka dengan ini peneliti rumusan masalah adalah "Seberapa besar pengaruh gaya kepemimpinan dan budaya organisasi terhadap kinerja karyawan secara simultan pada Bank BTN Kantor Cabang Tangerang?".

\section{Kerangka Berfikir}

Gaya Kepemimpinan (X1)

1. Gaya kepemimpinan eksekutif

2. Gaya kepemimpinan pecinta pengembangan (developer)

3. Gaya kepemimpinan otokratis yang baik hati 
JURNAL ILMIAH

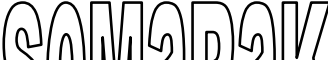

P-ISSN 2615-6849, E-ISSN 2622-3686

Jurnal Semarak,Vol. 2,No.1, Februari 2019, Hal (21 - 30)

@ Prodi Manajemen Fakultas Ekonomi Universitas Pamulang

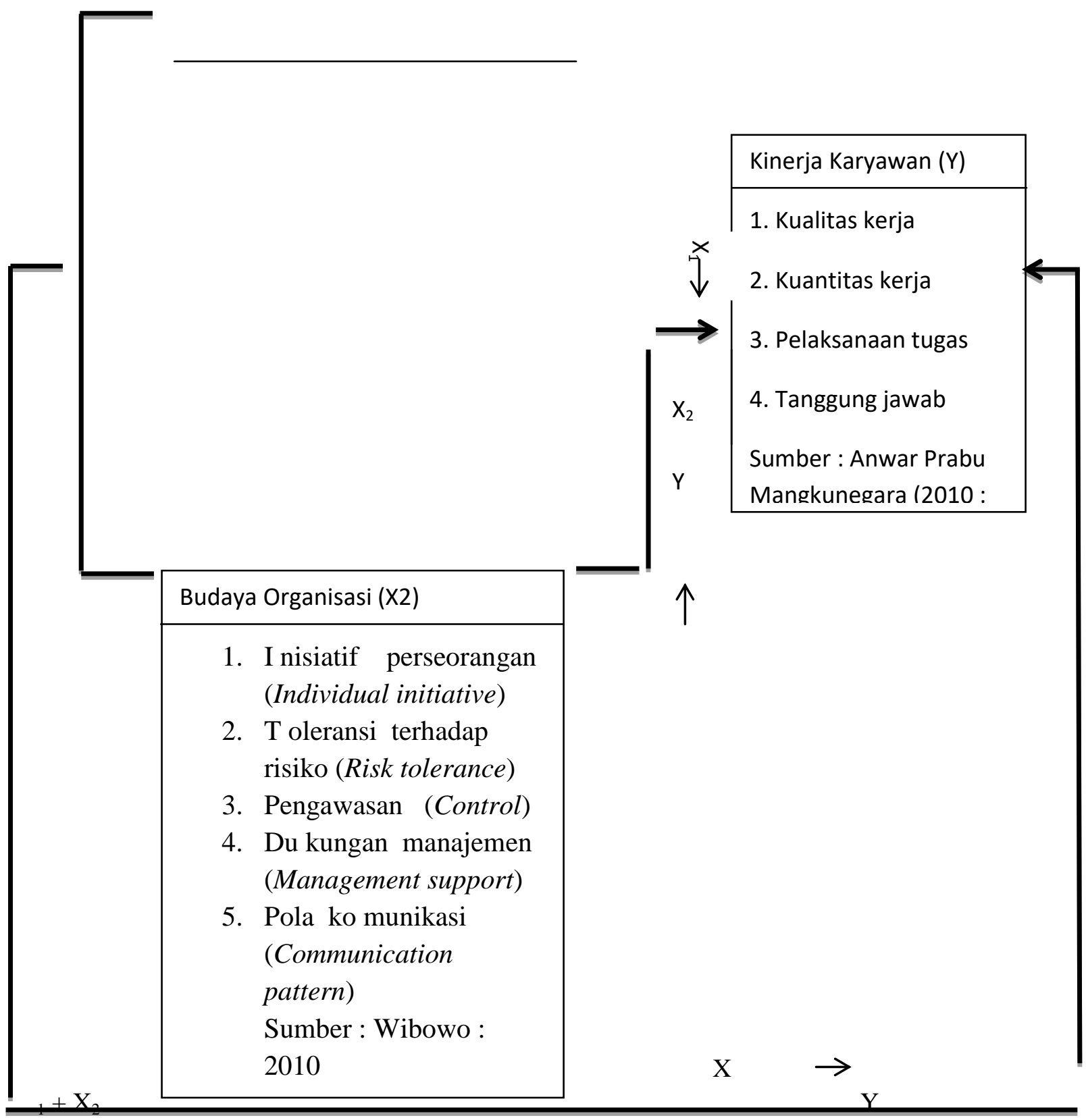

$\mathrm{H}$

\section{E. Hipotesis}

Rumusan hipotesis yang diketengahkan dalam penelitian ini sebagaimana gambar diatas adalah sebagai 
"Terdapat pengaruh gaya kepemimpinan dan budaya organisasi terhadap kinerja karyawan secara simultan pada Bank BTN Kantor Cabang Tangerang".

\section{TINJAUAN PUSTAKA}

\section{A. Gaya Kepemimpinan}

Pemimpin adalah seseorang yang memiliki kemampuan untuk dapat memperngaruhi, mengatur, mengarahkan serta mengkoordinir orang lain untuk berkerja sama dalam mencapai suatu tujuan tertentu. Sedangkan kepemimpinan adalah cara seseorang untuk memperngaruhi orang lain sehingga orang tersebut mau berkerja sama untuk mencapai suatu tujuan tertentu.

Menurut George R. Terry (Miftah Thoha, 2010: 5) bahwa Kepemimpinan adalah "aktivitas untuk mempengaruhi orang-orang supaya diarahkan mencapai tujuan organisasi".

\section{B. Budaya Organisasi}

Pengertian Rivai dan Mulyadi (2012:373), bahwa "Pengertian budaya menurut definisi, budaya itu sukar dipahami, tidak berwujud, implisit dan dianggap sudah semestinya atau baku. Definisi lain menyebutkan budaya adalah sejumlah pemahaman penting seperti norma, nilai, sikap, dan keyakinan yang dimiliki bersama oleh anggota organisasi."

Pengertian Laudon dan Laudon (2012:97), bahwa "Organisasi adalah struktur formal yang stabil dan formal yang mengambil sumber daya dari lingkungan dan memprosesnya untuk menciptakan output". Menurut para ahli Robbins dan Judge (2014), bahwa "Kultur organisasi (organizational culture) mengacu pada sebuah sistem makna bersama yang dianut oleh para anggota yang membedakan organisasi tersebut dengan organisasi lainnya".

\section{Kinerja Karyawan}

Menurut Mangkunegara (2013) kinerja "merupakan hasil kerja secara kualitas dan kuantitas yang dicapai oleh seseorang dalam melaksanakan fungsinya sesuai dengan tanggungjawab yang diberikan kepadanya.

Lain hal dengan, Siagian (2016) mendefinisikan pengertian Kinerja "sebagai suatu keseluruhan kemampuan seseo rang untuk bekerja sedemikian rupa sehingga mencapai tujuan kerja secara optimal dan berbagai sasaran yang telah diciptakan dengan peng orbanan yang secara rasio lebih kecil dibandingkan dengan hasil yang dicapai”.

\section{METODELOGI PENELITIAN}

\section{A. Ruang lingkup Penelitian}

Yang telah menjadi objek penelitian ialah Bank BTN Kantor Cabang Tangerang yang beralamat di Jl. Perintis Kemerdekaan No. 1, Cikokol Tangerang 15118 Telp. 021-5539363 Fax. 0215537977.

\section{B. Poppulasi dan Sampel}

Populasi yang akan ingin dijadikan objek dalam penelitian ini ialah seluruh karyawan Bank BTN Kantor Cabang Tangerang sebanyak 203 orang.

Sedangkan teknik cara pengambilan sampel ialah menggunakan rumus Slovin Azhari (2010) sebagai berikut : 


$$
n=\frac{N}{1+N\left(e^{2}\right)}
$$

Jumlah sampel penelitian ini sebanyak 67 karyawan

Metode cara pengumpulan data meliputi pengumpulan data primer dan pengumpulan data sekunder.

\section{Metode Analis Data}

Metode analisis data meliputi analisis deskriptif, pengujian instrumen data (uji kualitas data) yang terdiri dari "uji validitas" dan "uji reliabilitas". Kemudian pengujian kelayakan data (asumsi klasik) yang terdiri dari "uji normalitas", "uji multikolinieritas", "uji heterokedastisitas" dan "uji autokorelasi", analisis data (uji statistik) yaitu "regresi linear sederhana", "uji korelasi product moment" dan "analisis koefisien determinasi" serta "uji hipotesis/uji t"

\section{Operasional Variabel}

Variabel pada penelitian terdiri dari Gaya Kepemimpinan, Budaya Organisasi dan Kinerja Karyawan

HASIL PENELITIAN DAN PEMBAHASAN

\section{A. Gambaran Umum Objek Penelitian}

Kajian konsultan independent, "Price Water House Coopers, pemerintah melalui menteri BUMN dalam surat No. 5 - 544/MMBU/2002 memutuskan Bank BTN (Persero) sebagai Bank umum dengan fokus bisnis pembiayaan perumahan tanpa subsidi".

\section{B. Analisis Deskriptif Karakteristik Responden}

Kuesioner dalam penelitian ini terdiri dari 67 res ponden yang akan menjadi sampel dalam penelitian, dilakukan pembedaan terhadap jenis kelamin, dan usia karyawan. Gambaran data responden karyawan Bank BTN Kantor Cabang Tangerang sebagai berikut :

\section{Ber dasarkan Jenis Kelamin}

Jumlah responden berdasarkan jenis kelamin dapat dilihat pada tabel berikut

\begin{tabular}{lr|r|r|r} 
& $\begin{array}{c}\text { Jenis Kelamin } \\
\text { Frequen } \\
\text { cy }\end{array}$ & Percent & Valid & $\begin{array}{c}\text { Cumulati } \\
\text { ve } \\
\text { Percent }\end{array}$ \\
Percent \\
\hline Laki-laki & 47 & 70.1 & 70.1 & 70.1 \\
\hline Perempuan & 20 & 29.9 & 29.9 & 100.0 \\
\hline Total & 67 & 100.0 & 100.0 & \\
& & & & \\
\hline \multicolumn{3}{c}{ Tabel 1 }
\end{tabular}

Sumber : hasil pengolahan data

\section{Berdasarkan Usia}

Perbedaan kondisi karyawan seperti usia dapat menunjukkan perilaku responden dalam kinerja karyawan. Pengelompokkan ini bertujuan untuk mengetahui kinerja karyawan dari kelompok usia yang lebih berpotensi bekerja secara optimal pada Bank BTN Kantor Cabang Tangerang : 
JURNAL ILMIAH

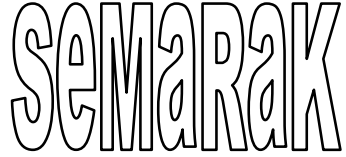

Tabel 2

\section{Jumlah Responden BerdasarkanUsia}

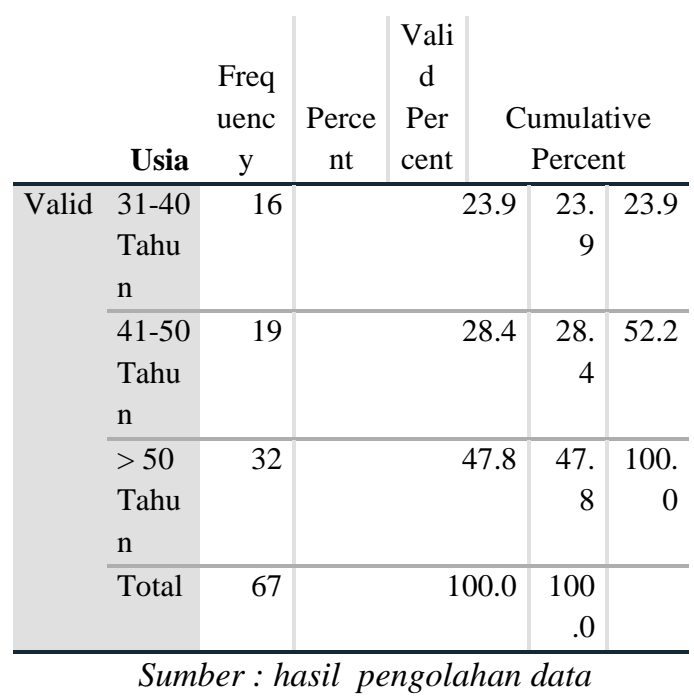

\section{Pengujian Instrumen Data}

Pengujian instrumen diperlukan untuk mengetahui bahwa variabel yang diteliti memiliki fungsi sebagai alat pembuktian.

\section{a. Uji Validitas}

Taraf nilai signifikansi $\alpha=0,05$ dengan tingkat pengujiannya $95 \%$. Berikut ini hasil perhitungan uji validitas setiap variabel yang digunakan, yaitu:
Tabel 3

Uji Validitas Variabel $\mathbf{X}_{\mathbf{1}}, \mathbf{X}_{\mathbf{2}}, \mathbf{Y}$ Sumber :hasil pengolahan data

\begin{tabular}{|c|c|c|c|c|c|}
\hline $\begin{array}{c}\text { No. } \\
\text { B } \\
\text { utir } \\
\begin{array}{c}\text { Pern } \\
\text { yataa } \\
\mathrm{n}\end{array}\end{array}$ & $\begin{array}{c}\mathrm{r} \\
\text { Hitung } \\
\text { Varia } \\
\text { bel X1 }\end{array}$ & $\begin{array}{c}\mathrm{r} \\
\text { Hitung } \\
\text { Varia } \\
\text { bel } \\
\mathrm{X} 2\end{array}$ & $\begin{array}{c}\mathrm{r} \\
\text { Hitun } \\
\mathrm{g} \\
\text { Varia } \\
\text { bel Y }\end{array}$ & $\mathrm{r}_{\text {tabel }}$ & Keputusan \\
\hline 1 & 0,429 & 0,418 & 0,368 & 0,240 & V alid \\
\hline 2 & 0,430 & 0,478 & 0,598 & 0,240 & V alid \\
\hline 3 & 0,346 & 0,431 & 0,381 & 0,240 & V alid \\
\hline 4 & 0,613 & 0,526 & 0,509 & 0,240 & V alid \\
\hline 5 & 0,810 & 0,568 & 0,555 & 0,240 & V alid \\
\hline 6 & 0,514 & 0,425 & 0,542 & 0,240 & V alid \\
\hline 7 & 0,746 & 0,618 & 0,678 & 0,240 & V alid \\
\hline 8 & 0,822 & 0,498 & 0,540 & 0,240 & V alid \\
\hline 9 & 0,802 & 0,433 & 0,714 & 0,240 & V alid \\
\hline 10 & 0,410 & 0,638 & 0,499 & 0,240 & V alid \\
\hline
\end{tabular}

\section{b. Uji Reliabilitas}

Taraf nilai signifikansi $\alpha=0,05$ (5\%) dengan adalah 95\%. Berikut ini hasil perhitungan uji reliabilitas pada masingmasing variabel, sebagai berikut :

Tabel 4

Uji Re liabilitas Data

Sumber : hasil pengolahan data

\begin{tabular}{|c|c|c|c|c|}
\hline No & $\begin{array}{c}\mathrm{V} \\
\text { ariabel }\end{array}$ & $\begin{array}{c}\mathbf{r} \\
\text { hitun } \\
\mathbf{g}\end{array}$ & $\begin{array}{c}r \\
\text { table }\end{array}$ & $\underset{\mathbf{n}}{\text { Kesimpula }}$ \\
\hline 1 & $\begin{array}{l}\text { Gaya } \\
\text { Kepemim } \\
\text { inan }\left(\mathrm{X}_{1}\right)\end{array}$ & $\begin{array}{c}0 \\
, 791\end{array}$ & $\begin{array}{c}0 \\
240\end{array}$ & Re liabel \\
\hline 2 & $\begin{array}{l}\text { Organisas } \\
\mathrm{i}\left(\mathrm{X}_{2}\right)\end{array}$ & $\begin{array}{c}0 \\
.673\end{array}$ & $\begin{array}{c}0 \\
240\end{array}$ & Re liabel \\
\hline 3 & $\begin{array}{l}\text { Ki nerja } \\
\text { Karyawa } \\
\mathrm{n}(\mathrm{Y})\end{array}$ & $\begin{array}{c}0 \\
, 731\end{array}$ & $\begin{array}{c}0 \\
240\end{array}$ & R eliabel \\
\hline
\end{tabular}




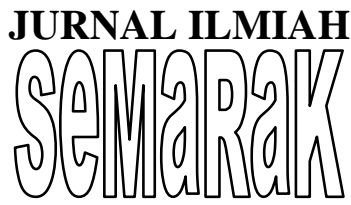

c. Pengujian Kelayakan Data (Asumsi Klasik)

\section{1.) Uji Normalitas}

\section{Tests of Normality}

\begin{tabular}{|c|c|c|c|c|c|c|}
\hline & \multicolumn{3}{|c|}{$\begin{array}{l}\text { Kolmogorov- } \\
\text { Smirnov }^{\mathrm{a}}\end{array}$} & \multicolumn{3}{|c|}{ Shapiro-Wilk } \\
\hline & $\begin{array}{l}\text { "Stati } \\
\text { stic" }\end{array}$ & $\begin{array}{l}\text { "Df } \\
"\end{array}$ & "Sig. & $\begin{array}{l}\text { "Statis } \\
\text { tic" }\end{array}$ & "Df & $\begin{array}{l}\text { "Si } \\
\text { g." }\end{array}$ \\
\hline "Kinerja & “.076 & "10 & “.164 & ".973" & "10 & “.03 \\
\hline $\begin{array}{l}\text { Karyawan } \\
(\mathrm{Y}) ”\end{array}$ & ” & $0 "$ & $"$ & & $0 "$ & $6 "$ \\
\hline
\end{tabular}

"a. Lilliefors Significance Correction"

"Sumber :hasil pengolahan data"

2.) Uji Heteros kedastisitas

\begin{tabular}{|c|c|c|c|c|c|c|c|}
\hline \multicolumn{8}{|c|}{ Coefficients $^{\mathbf{a}}$} \\
\hline Model & \multicolumn{2}{|c|}{$\begin{array}{c}\text { Unstand } \\
\text { ardized } \\
\text { Coefficie } \\
\text { nts } \\
\text { Std. } \\
\text { Erro }\end{array}$} & $\begin{array}{c}\text { Standar } \\
\text { dized } \\
\text { Coeffic } \\
\text { ients } \\
\text { Beta }\end{array}$ & $\mathrm{T}$ & $\begin{array}{l}\mathrm{Si} \\
\text { g. }\end{array}$ & \multicolumn{2}{|c|}{$\begin{array}{c}\text { Collin } \\
\text { earity } \\
\text { Statisti } \\
\text { cs }\end{array}$} \\
\hline 1 (Constar & $\begin{array}{r}9 . \\
83 \\
9\end{array}$ & $\begin{array}{r}3.65 \\
2\end{array}$ & & $\begin{array}{r}2 . \\
69 \\
4\end{array}$ & $\begin{array}{l}.0 \\
0 \\
9\end{array}$ & & \\
\hline $\begin{array}{l}\text { Gaya } \\
\text { Kepemimpi } \\
\text { nan (X1) }\end{array}$ & $\begin{array}{r}.3 \\
55\end{array}$ & .096 & .403 & $\begin{array}{r}3 . \\
68 \\
9\end{array}$ & $\begin{array}{l}.0 \\
0 \\
0\end{array}$ & $\begin{array}{l}.6 \\
4 \\
2\end{array}$ & $\begin{array}{r}1 . \\
55 \\
7\end{array}$ \\
\hline $\begin{array}{l}\text { Budaya } \\
\text { Organisasi } \\
\text { (X2) }\end{array}$ & $\begin{array}{r}.4 \\
07\end{array}$ & .113 & .395 & $\begin{array}{r}3 . \\
61 \\
4\end{array}$ & $\begin{array}{l}.0 \\
0 \\
1\end{array}$ & $\begin{array}{l}.6 \\
4 \\
2\end{array}$ & $\begin{array}{r}1 . \\
55 \\
7\end{array}$ \\
\hline
\end{tabular}

a. Dependent Variable: Kinerja Karyawan (Y)

\section{3.)}

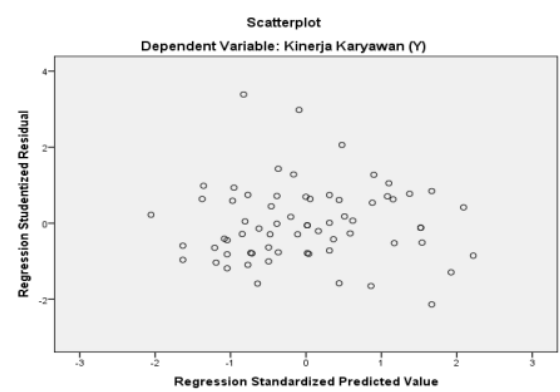

"Sumber : Data primer yang diolah"

Gambar 2

Hasil Uji Heteroskedast

Pada gambar di atas, titik-titik pada grafik scatterplot titik- titik diatas tersebut telah menyebar di atas dan dibawah pada angka 0 pada sumbu $Y$, dengan demikian menunjukkan bahwa tidak terdapat gangguanheteroskedastisitas.

\section{4.) Uji Multikolinearitas}

\section{Tabel 6}

Berdasarkan tabel di atas, diperoleh nilai tolerance gaya kepemimpinan dan budaya organisasi sebesar 0.642

\section{5.) "Uji Auto korelasi"}

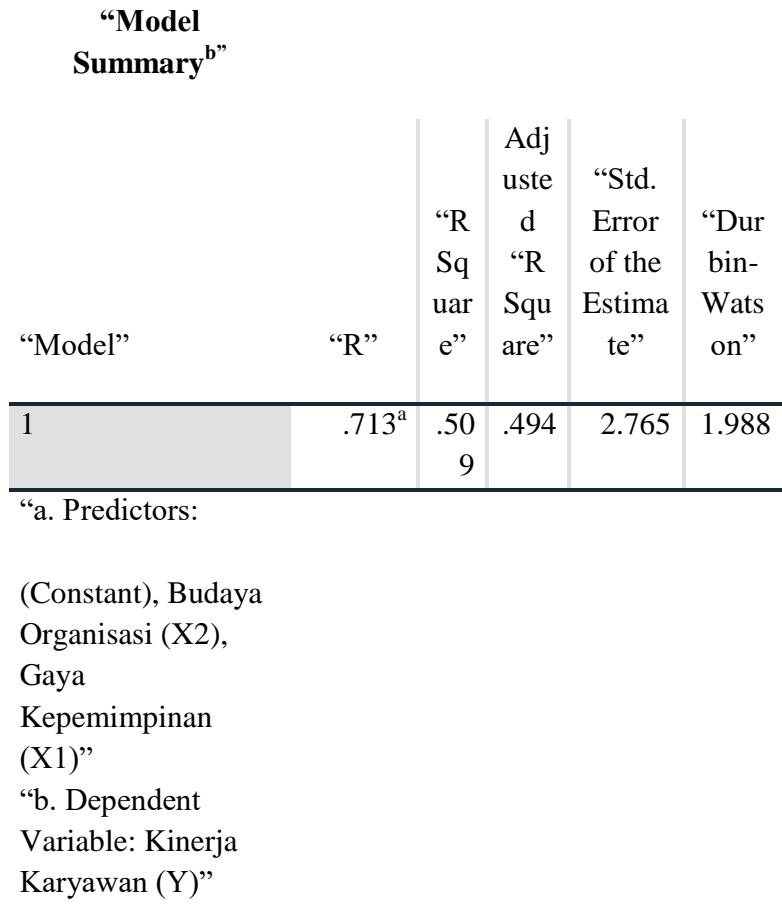


JURNAL ILMIAH

candony

sumber :hasil pengolahan data

Sesuai dengan ketentuan maka model regresi ini tidak ada autokorelasi. Dengan demikian kuesioner layak untuk diolah sebagai data penelitian.

\section{b. Analisis Data (Uji Statistik)}

\section{Correlations $^{b}$}

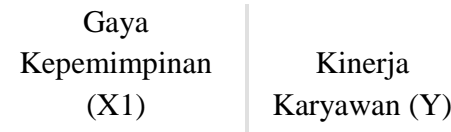

\begin{tabular}{|c|c|c|c|}
\hline \multirow{3}{*}{$\begin{array}{l}\text { Gaya } \\
\text { Kepemimpinan } \\
\text { (X1) }\end{array}$} & Pe arson & \multirow[t]{3}{*}{1} & \multirow{3}{*}{$\begin{array}{r}.639^{* *} \\
.000\end{array}$} \\
\hline & Corre lation & & \\
\hline & $\begin{array}{l}\text { Sig. (2- } \\
\text { tailed) }\end{array}$ & & \\
\hline \multirow{3}{*}{$\begin{array}{l}\text { Kinerja } \\
\text { Karyawan (Y) }\end{array}$} & $\mathrm{Pe}$ arson & $.639^{* *}$ & 1 \\
\hline & Correl ation & & \\
\hline & $\begin{array}{l}\text { Sig. (2- } \\
\text { tailed) }\end{array}$ & .000 & \\
\hline
\end{tabular}

**. Corre lation is signi ficant at the 0.01 level (2-tailed).

b. Listwise $\mathrm{N}=67$

\section{Correlations $^{\mathrm{b}}$}

Budaya
Organisasi

Kinerja

Organisasi

(X2)

Karyawan

(Y)

\begin{tabular}{|c|c|c|c|}
\hline \multirow{3}{*}{$\begin{array}{l}\text { Budaya } \\
\text { Organisasi (X2) }\end{array}$} & & \multirow[t]{3}{*}{1} & \multirow[t]{2}{*}{$.636^{* * *}$} \\
\hline & Corre lation & & \\
\hline & $\begin{array}{l}\text { Sig. (2- } \\
\text { tailed) }\end{array}$ & & .000 \\
\hline \multirow{2}{*}{$\begin{array}{l}\text { Kinerja } \\
\text { Karyawan (Y) }\end{array}$} & Pear son & $.636^{* *}$ & 1 \\
\hline & $\begin{array}{l}\text { Sig. (2- } \\
\text { tailed) }\end{array}$ & .000 & \\
\hline \multicolumn{4}{|c|}{$\begin{array}{l}* * \text {. Corre lation is signify cant at the } 0.01 \text { level } \\
\text { (2-tailed). } \\
\text { b. Listwise } N=67\end{array}$} \\
\hline
\end{tabular}

Berdasarkan tabel di atas, diperoleh nilai koefisien korelasi sebesar 0 . 636, maka disimpulkan variabel "budaya organisasi” memiliki tingkat hubungan kuat terhadap"kinerja karyawan".

Sumber :hasil pengolahan data

\begin{tabular}{|c|c|c|c|c|c|}
\hline & Co & ficient & & & \\
\hline & $\begin{array}{r}\text { Un } \\
\mathrm{d} \\
\text { Coef }\end{array}$ & $\begin{array}{l}\text { andar } \\
\text { ced } \\
\text { cients }\end{array}$ & $\begin{array}{l}\text { Standar } \\
\text { dized Co } \\
\text { efficients }\end{array}$ & & \\
\hline Modell & B & Error & Beta & $\mathrm{t}$ & Sig. \\
\hline $1 \quad$ (Consstant) & 9.839 & 3.652 & & $\begin{array}{r}2.69 \\
4\end{array}$ & $\begin{array}{r}.00 \\
9\end{array}$ \\
\hline $\begin{array}{l}\text { Gaya } \\
\text { Kepemimpinan } \\
\text { (X1) }\end{array}$ & .355 & .096 & .403 & $\begin{array}{r}3.68 \\
9\end{array}$ & $\begin{array}{r}.00 \\
0\end{array}$ \\
\hline $\begin{array}{l}\text { Budaya } \\
\text { Organisasi (X2) }\end{array}$ & .407 & .113 & .395 & $\begin{array}{r}3.61 \\
4\end{array}$ & $\begin{array}{r}.00 \\
1\end{array}$ \\
\hline
\end{tabular}

Tabel 


\section{3.) Pengujian Hipotesis}

\section{4.) Tabel 11}

\section{Hasil Uji t $\mathrm{X}_{1}$ Terhadap $\mathrm{Y}$}

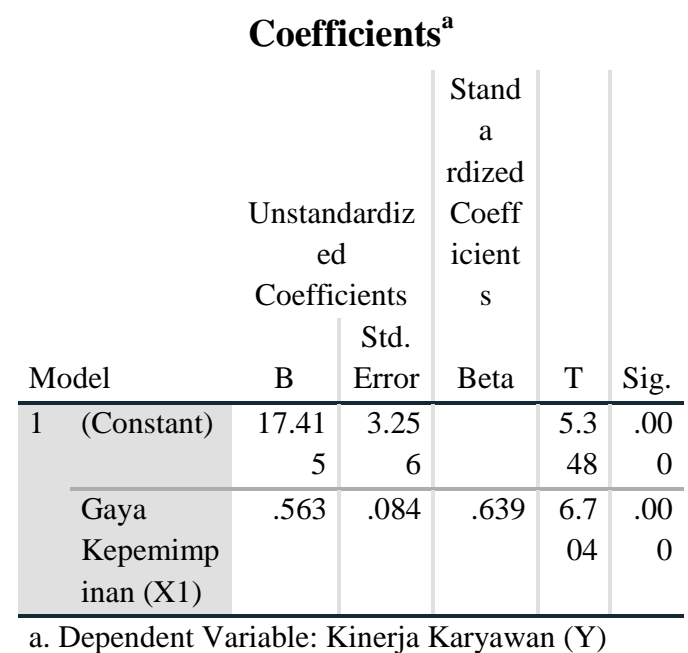

Sumber :hasil pengolahan data

(b). Pengaruh Budaya Organisasi $\left(\mathrm{X}_{2}\right)$ Terhadap Kinerja Karyawan (Y)

\section{Tabel 12}

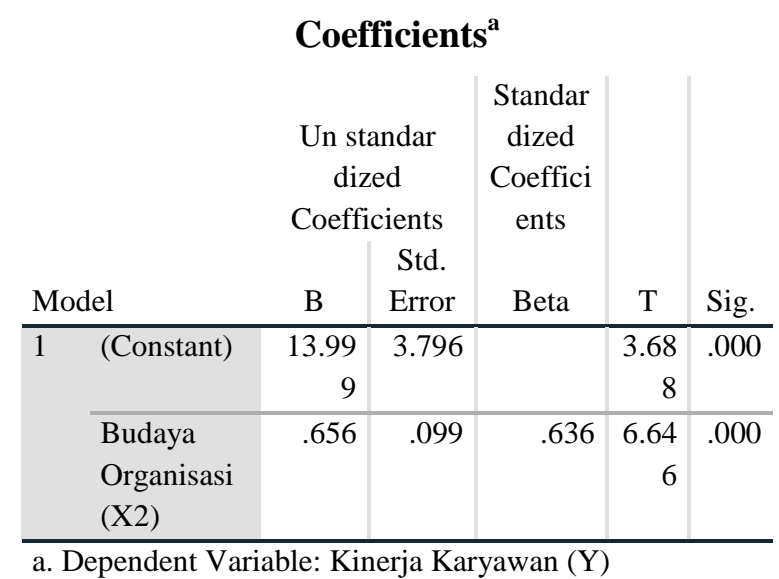

\section{Hasil Uji t $\mathbf{X}_{2}$ Terhadap Y}

Sumber :hasil pengolahan data
Tabel 17

Hasil Uji Hipotesis

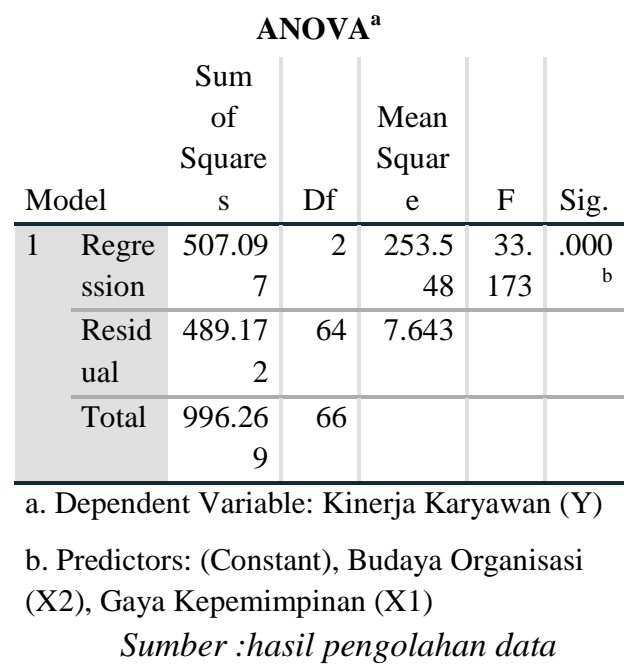

\section{PENUTUP}

\section{A. KE SIMPULAN}

Berdasarkan denganhasil penelitian, maka penulis telah menarikkesimpulan sebagai berikut :

1. Pengaruh yang diberikan oleh variabel tersebut digambarkan dengan thitung > ttabel $(6,704>$ 1,997) sehingga dinyatakaatn dap berpengaruh possitif dan signifikan secara parsial gaya kepemimpinan terhadap kinerja karyawan

2. Pengaruh yang diberikan oleh variabel tersebut digambarkan dengan thitung > ttabel $(6,646>$ 1,997) dinyatakan berpengaruh positif dan signifikan secara parsial antara budaya organisasi terhadap kinerja karyawan

3. Dari Uji F yang memberikan hasil Fhitung > Ftabel $(33,173$ > 3,140) maka Ha diterima, sehingga dinyatakan bahwa terdapat pengaruh yang positif 
dan signifikan secara bersamasama antara variabel gaya kepemimpinan dan budaya organisasi terhadap kinerja karyawan Bank BTN Kantor Cabang Tangerang.

\section{SARAN}

Berikut saran yang dapat di sampaikan :

1. Pemimpin perlu mengupayakan dalam memberikan pengarahan yang jelas untuk meningkatkan gaya kepemimpinan khususnya yang berhubungan dengan kinerja karyawan.

2. Manajemen bisa lebih menghargai pendapat/ide, serta tenaga dari karyawan, agar karyawan merasa dihargai dalam mengemukakan pendapatnya, sehingga karyawan bisa me musatkan perhatian, pikiran serta tenaganya untuk melaksanak an tugas yang di percayakan kepadanya. Maka dari itu, bagian kepegawaian GBA (General Brand Administration) Bank BTN Kantor Cabang Tangerang wajib memberikan info pengembangan karir secara transparan, obyektif dan kontinyu kepada semua karyawan. Selain itu peng embangan karir dalam aspek individu maupun organisasi dapat dilakukan secara sinergis dan berkelanjutan sehingga karirr karyawan akan terarah menuju profesional.
3. Diharapkan bagi peneliti selanjutnya untuk dapat mengembangkan faktor-faktor lain terkait pengelolaan sumber daya manusia yang dihubungkan dengan kinerja karyawan suatu perusahaan misalnya gaya kepemimpinan atau budaya organisasi untuk dijadikan variabel penelitian

\section{DAFTAR PUSTAKA}

Hariandja, M. T. (2012). Manajemen Sumber Daya Manusia. Jakarta: Grasindo.

Mangkunegara, A. P. (2013). Manajemen Sumber Daya Manusia Perusahaan. Bandung: Rosdakarya.

Robbins, S. P. (2010). Perilaku Organisasi. Jakarta: Salemba Empat.

Siagian, S. P. (2016). Manajemen Sumber Daya Alam. Jakarta: Bumi Aksara.

Sugiyono. (2010). Metode Penelitian Bisnis. Jakarta: CV. Alfabeta.

Thoha, M. (2010). Perilaku Organisasi, Konsep Dasar Aplikasinya. Jakarta: CV. Rajawali.

Wibowo. (2014). Manajemen Kinerja (Edisi Keempat). Jakarta: Raja Grafindo Persada. 
JURNAL ILMIAH

(2) 0 ilg DG

0) 5 (1) (
P-ISSN 2615-6849, E-ISSN 2622-3686

Jurnal Semarak,Vol. 2,No.1, Februari 2019, Hal (21- 30)

@ Prodi Manajemen Fakultas Ekonomi Universitas Pamulang 